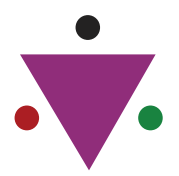

IJCRR

Section: Healthcare

Sci. Journal Impact

Factor: 6.1 (2018)

ICV: 90.90 (2018)

Scopus'

\title{
A Study on Effect of Smokeless Tobacco on Pulmonary Function Tests in Class IV Workers of USM-KLE (Universiti Sains Malaysia-Karnataka Lingayat Education Society) International Medical Programme, Belagavi
}

\author{
Varsha M. Shindhe ${ }^{1}$, Maheshkumar M. Shindhe ${ }^{2}$, Neha S. Kulkarniं ${ }^{3}$, \\ Madiha Mehvish ${ }^{4}$, Shivalingappa B. Javali ${ }^{5}$, Fareeda Banu Balikai ${ }^{6}$, \\ Kamaruddin Jaalam ${ }^{7}$
}

\begin{abstract}
'Assistant Professor, Department of Physiology, USM KLE International Medical Programme and Kaher's Jawaharlal Nehru Medical College, Belagavi; ${ }^{A}$ Assistant Professor, Department of Community Medicine, Belagavilnstitute of Medical Sciences, Belagavi; ${ }^{3}$ Associate professor, Department of Physiology, Kaher's]awaharlal Nehru Medical College, Belagavi; ${ }^{4}$ Assistant professor, Department of Physiology, USM KLE Interna-

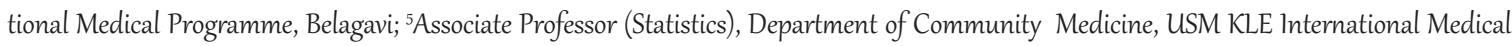
Programme, Belagavi; ${ }^{\circ}$ Associate professor, Department of Physiology, USM KLE International Medical Programme, Belagavi; Deputy Dean, USM KLE International Medical Programme, Belagavi, India and Professor, and Consultant Anaesthesiologist - Intensivist, Department of Anaesthesiology and Intensive Care, Hospital Universiti Sains Malaysia, School of Medical Sciences, Health Campus, Universiti Sains Malaysia 16150 Kubang Kerian, Kelantan, Malaysia
\end{abstract}

\section{ABSTRACT}

Background: Tobacco use is become a public health issue in India and worldwide as well. Due of vigorous efforts towards increasing awareness of the adverse effects of tobacco, smoking has declined and the use of smokeless tobacco has been increased paradoxically among adolescents considering it as safe alternatives of smoking. Through previous studies, it is known that tobacco smoking can adversely affect the respiratory system, yet there are very few studies that have thrown light on the deleterious effects of smokeless tobacco on respiratory system.

Objective: To evaluate effect of tobacco chewing on Pulmonary Functions and to compare the results with non-tobacco chewers in class 4 workers of USM KLE International Medical Programme, Belagavi.

Methods: Pulmonary function tests were carried out on a total 130 volunteering male and female participants, in the age group of 25-55 years. Spirometric parameters such as Forced Vital Capacity, Forced Expiratory Volume in 1st second, FEV1/FVC ratio, Peak Expiratory Flow Rate, Forced expiratory flow between 0.2 to $1.2 \mathrm{~L}$ of expiration, Maximum mid expiratory flow rate or FEF25-75 and Maximal Voluntary Ventilation were compared between 65 tobacco users and 65 apparently healthy, non tobacco users of same socioeconomic status matched for age, sex, height and weight.

Results: There was significant reduction in the values of all PFT parameters except FEV1/FVC in tobacco chewers compared to non tobacco chewers ( $p<0.001)$, suggesting restrictive impairment in tobacco chewers.

Conclusion: Hence we conclude that the use of smokeless tobacco in the form of chewing has deleterious effects on lung functions that could be attributed to oxidative stress caused by smokeless tobacco.

Key Words: Oxidative stress, Pulmonary function tests, Restrictive lung disease, Smokeless tobacco (SLT)

\section{INTRODUCTION}

Tobacco use is become a public health issue in India and worldwide as well. Tobacco is mainly consumed in two forms: smoked tobacco and smokeless tobacco. The use of tobacco without burning is referred to as Smokeless tobacco (SLT). Smokeless tobacco is used as chewed, sniffed or sucked form ${ }^{1}$.

Smokeless tobacco (SLT) use has been increased rapidly throughout the world, especially among adolescents by con-

\section{Corresponding Author:}

Dr. Maheshkumar M. Shindhe, Assistant Professor, Department of Community Medicine, Belagavi Institute of Medical Sciences, Belagavi. Ph: 9448218393; Email: docmaheshms@gmail.com

ISSN: $2231-2196$ (Print)

Received: 28.03.2020
ISSN: 0975-5241 (Online)

Revised: 03.05 .2020
Accepted: 11.06 .2020
Published: 22.07 .2020 
sidering it as safe alternative of smoking. Due to vigorous efforts towards increasing awareness of the adverse effects of tobacco, smoking has been declined and paradoxically the use of SLT has been greatly increased. ${ }^{1}$

Although it is well known that tobacco smoking adversely affects respiratory system causing chronic bronchitis, emphysema, chronic obstructive pulmonary disease and bronchial carcinoma, the deleterious effects of smokeless tobacco on respiratory system are yet to be explored. ${ }^{2}$

Tobacco contains various chemicals like nicotine, carbon monoxide and tar. In India, tobacco consumption is an important risk factor for development of various cardiovascular diseases and chronic obstructive pulmonary diseases ${ }^{3}$.

Expenditure on tobacco has been found significantly higher in proportion of their daily income in India. Use of smokeless tobacco indeed represents a health concern of growing magnitude. ${ }^{4}$

In contrast to voluminous literatures on the ill effects of smoking, relatively little attention has been directed at smokeless tobacco and the factors that promote its use. This study attempts to find out whether chewing tobacco causes any unfavorable effects to the lungs by using Pulmonary Function tests.

\section{AIMS AND OBJECTIVES}

1) To study Pulmonary Function tests by spirometry in tobacco chewers

2) To study Pulmonary Function tests in apparently healthy nontobacco chewers

3) To compare the test results between the two groups

\section{MATERIAL AND METHODS}

The study was conducted at the Department of Physiology, USM KLE International Medical Programme, Belagavi.

Study design: This is a comparative, case control study.

Duration of study: 8 months (April 2019 to November 2019)

\section{Population under study}

Class IV workers of USM KLE International Medical Programme, Belagavi, in the age group of 25-55 years who consume oral tobacco. Age and sex matched controls who do not consume tobacco.

Both controls and cases were from same socioeconomic status and were involved in the same occupation.

Sample size: A total of 130 subjects were recruited into the study amongst which 70 were males and 60 were females.

\section{Selection criteria for study group}

\section{Inclusion criteria}

1. All apparently healthy volunteering participants of same socioeconomic status

2. Exclusive smokeless tobacco users.

\section{Exclusion criteria}

1. History of smoking

2. History of diabetes mellitus and hypertension

3. H/o chronic obstructive pulmonary disease, congenital cardiopulmonary diseases

4. History of Kyphosis, scoliosis

5. History of biomass exposure in females

6. History of occupational hazards.

\section{Method of collection of data}

Before initiation of the study ethical approval was taken from the Institutional Ethics Committee of USM KLE International Medical Programme, Belagavi. The details of the procedure was explained to the participants in their vernacular language and an informed written consent was obtained from them.

Data on Name, age, sex, occupation, and personal habits of the subjects was recorded using proformas and personal interviews with the subjects.

The basic parameters like age, weight, height and BMI of subjects were recorded. Pulmonary function tests were performed by using computerized RMS HELIOS 702-Spirometer. All the tests were conducted between 10 am to $1 \mathrm{pm}$ to avoid effects of diurnal variation. Overnight abstinence from tobacco use in any form was recommended. Subjects were asked to avoid tea, coffee, carbonated drinks or heavy meals at least two hours before the test procedure.

During the recording of PFT-The subject was asked to sit comfortably in a chair. Subject was instructed to breathe in fully by deep inspiration with nostrils closed by using nose clips. The lips were sealed around the sterile disposable mouthpiece of spirometer and air was forcefully expired out, as rapidly and deeply as possible. The Pulmonary function tests recorded include Forced Vital Capacity (FVC in litres), Forced Expiratory Volume in first second ( $\mathrm{FEV}_{1}$ in litres), $\mathrm{FEV}_{1} / \mathrm{FVC}(\%)$, Forced expiratory flow rate $25 \%-75 \%$, Maximum Voluntary Ventilation (MVV in litres/minute) and Peak expiratory flow rate (PEFR in litres/minute). Best of three technically satisfactory performances as per recommendations of American Thoracic society were considered and interpreted. ${ }^{5}$

\section{Statistical analysis}

The data was statistically analyzed accordingly using SPSS Version 20.00 . 
1. All the parameter scores were expressed in terms of Mean \pm SD

2. Independent ' $t$ test' was performed to assess the significant difference between two groups with respective parameters

3. The statistical significance was set at $5 \%$ level of significance $(\mathbf{p}<\mathbf{0 . 0 5})$

\section{RESULTS}

In our study we had a total of 130 participants amongst which $70(53.85 \%)$ were males and $60(46.1 \%)$ were females.

The mean age in males was higher in cases than controls and it was statistically significant but there was no significant difference in the mean age of controls and cases in females.

It was observed that in both males and females there was no significant difference in the anthropometric parameters including height, weight and BMI of tobacco chewers and non- chewers as shown in tables I and II.

Table I: Comparison of Anthropometric parameters of tobacco users and non users in males

\begin{tabular}{lccc} 
Parameter & $\begin{array}{c}\text { Controls n=35 } \\
\text { Mean } \pm \text { SD }\end{array}$ & $\begin{array}{c}\text { Cases } n=35 \\
\text { Mean } \pm \text { SD }\end{array}$ & P-value \\
Age & $31.17 \pm 7.99$ & $35.97 \pm 8.10$ & $0.0150^{*}$ \\
Height & $168.82 \pm 6.22$ & $169.20 \pm 6.35$ & 0.6209 \\
Weight & $66.68 \pm 12.89$ & $65.22 \pm 10.37$ & 0.6040 \\
BMI & $23.42 \pm 3.87$ & $22.69 \pm 2.77$ & 0.3666 \\
\hline
\end{tabular}

Table II: Comparison of Anthropometric parameters of tobacco users and non users in females

\begin{tabular}{lccc} 
Parameter & $\begin{array}{c}\text { Controls } n=30 \\
\text { Mean } \pm \text { SD }\end{array}$ & $\begin{array}{c}\text { Casesn }=30 \\
\text { Mean } \pm \text { SD }\end{array}$ & P-value \\
Age & $29.72 \pm 7.11$ & $29.96 \pm 5.46$ & 0.8867 \\
Height & $159.25 \pm 6.46$ & $156.35 \pm 5.80$ & 0.0802 \\
Weight & $63.03 \pm 9.81$ & $50.19 \pm 9.02$ & 0.1303 \\
BMI & $24.80 \pm 3.21$ & $24.32 \pm 4.14$ & 0.6189 \\
\hline
\end{tabular}

In males, it is observed that there is an impairment of pulmonary functions in tobacco chewers compared to tobacco non chewers. All pulmonary function parameters such as FVC, FEV1, FEF 25-75\%, FEF 0.2-1.2. , PEFR and MVV except $\mathrm{FEV}_{1} / \mathrm{FVC}$ shows statistically significant difference between chewing tobacco users and non users as shown in table III and graph I.
Table III: Comparison of PFT parameters in tobacco users and nonusers in males

\begin{tabular}{|c|c|c|c|}
\hline PFT & $\begin{array}{c}\text { Controls } n=35 \\
\text { Mean } \pm \text { SD }\end{array}$ & $\begin{array}{l}\text { Cases } \mathbf{n}=35 \\
\text { Mean } \pm \mathbf{S D}\end{array}$ & P-value \\
\hline FVC & $3.11 \pm 0.93$ & $2.26 \pm 0.72$ & $0.0001^{*}$ \\
\hline $\mathrm{FEV}_{1}$ & $2.88 \pm 0.85$ & $2.14 \pm 0.68$ & $0.0002^{*}$ \\
\hline $\mathrm{FEV}_{1} / \mathrm{FVC}(\%)$ & $95.05 \pm 6.65$ & $94 \cdot 5 \pm 6.57$ & 0.7321 \\
\hline PEFR & $7 \cdot 38 \pm 1.11$ & $4.60 \pm 1.31$ & $0.0001^{*}$ \\
\hline $\mathrm{FEF}_{0.2-1.2}$ & $6.40 \pm 1.18$ & $4.92 \pm 1.91$ & $0.0001^{*}$ \\
\hline $\mathrm{FEF}_{25-75}$ & $5 \cdot 30 \pm 1.24$ & $3 \cdot 45 \pm 1.41$ & $0.0001^{*}$ \\
\hline MVV & $111.50 \pm 13.31$ & $91.40 \pm 22.42$ & $0.0001^{*}$ \\
\hline
\end{tabular}

FVC (Forced Vital Capacity)

FEV (Forced Expiratory Volume in first second)

PEFR (Peak Expiratory Flow Rate)

$\mathrm{FEF}_{\text {0.2-1.2. }}$ (Forced expiratory flow between 0.2 to $1.2 \mathrm{~L}$ of expiration)

$\mathrm{FEF}_{25-75}$ (forced expiratory flow between $25 \%$ and $75 \%$ of FVC) or MMFER (Maximum mid expiratory flow rate)

MVV (Maximal Voluntary Ventilation)

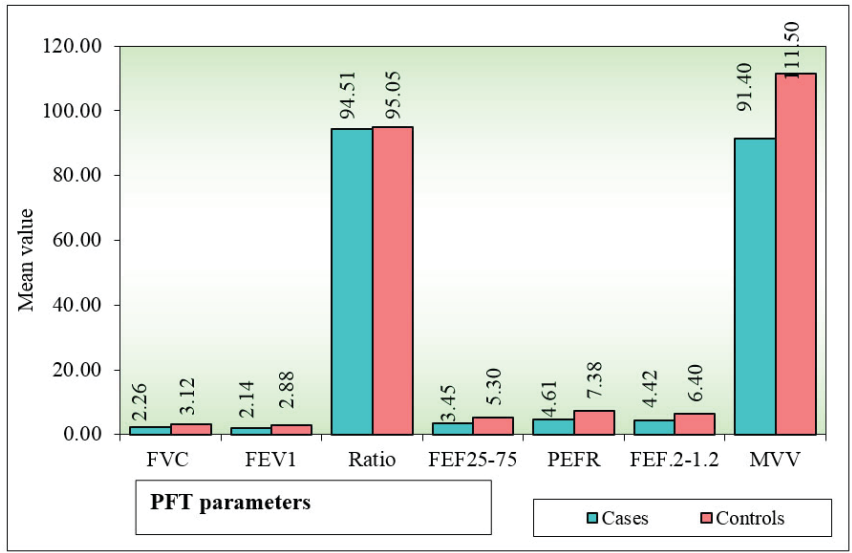

Graph I: Comparison of PFT parameters in tobacco users and nonusers in males

In females it is observed that, there is an impairment of pulmonary functions in tobacco chewers compared to tobacco non chewers. The difference in the mean values of pulmonary function parameters such as FVC, FEV1, FEV1/FVC, FEF25-75\%, $\mathrm{FEF}_{0.2-1.2}$, PEFR and MVV were highly significant in chewing tobacco users compared to non chewers as shown in table IV and graph II.

Table IV: Comparison of PFT parameters in tobacco users and nonusers in females

$\begin{array}{lccc}\text { PFT } & \begin{array}{c}\text { Controls n }=30 \\ \text { Mean } \pm \text { SD }\end{array} & \begin{array}{c}\text { Cases n }=30 \\ \text { Mean } \pm \text { SD }\end{array} & \text { P-value } \\ \text { FVC } & 1.95 \pm 0.45 & 1.36 \pm 0.36 & \text { o.ooo1 }^{*} \\ \mathrm{FEV}_{1} & 1.70 \pm 0.35 & 1.31 \pm 0.28 & \text { o.ooo1* }^{*} \\ \mathrm{FEV}_{1} / \mathrm{FVC}(\%) & 96.92 \pm 6.28 & 83.61 \pm 223.46 & \text { o.oo68 }^{*} \\ \text { PEFR } & 5.28 \pm 1.03 & 3.88 \pm 1.28 & \text { o.ooo1 }^{*}\end{array}$


Table IV: (Continued)

\begin{tabular}{lccc} 
PFT & $\begin{array}{c}\text { Controls n }=30 \\
\text { Mean } \pm \text { SD }\end{array}$ & $\begin{array}{c}\text { Cases n }=30 \\
\text { Mean } \pm \text { SD }\end{array}$ & P-value \\
$\mathrm{FEF}_{\text {o.2-1.2 }}$ & $4.24 \pm 1.15$ & $2.61 \pm 1.39$ & o.ooo1* $^{*}$ \\
$\mathrm{FEF}_{25-75}$ & $3.11 \pm 0.67$ & $2.80 \pm 1.18$ & $0.2116^{*}$ \\
$\mathrm{MVV}$ & $104.38 \pm 22.75$ & $70.78 \pm 20.94$ & o.ooo1 $^{*}$ \\
\hline
\end{tabular}

FVC (Forced Vital Capacity)

FEV $\left(\right.$ Forced Expiratory Volume in $1^{\text {st }}$ second).

PEFR (Peak Expiratory Flow Rate)

FEF $_{0.2-1.2}$ (Forced expiratory flow between 0.2 to 1.2 L of expiration)

$\mathrm{FEF}_{25-75}$ (forced expiratory flow between $25 \%$ and $75 \%$ of $\mathrm{FVC}$ ) or MMFER (Maximum mid expiratory flow rate)

MVV (Maximal Voluntary Ventilation)

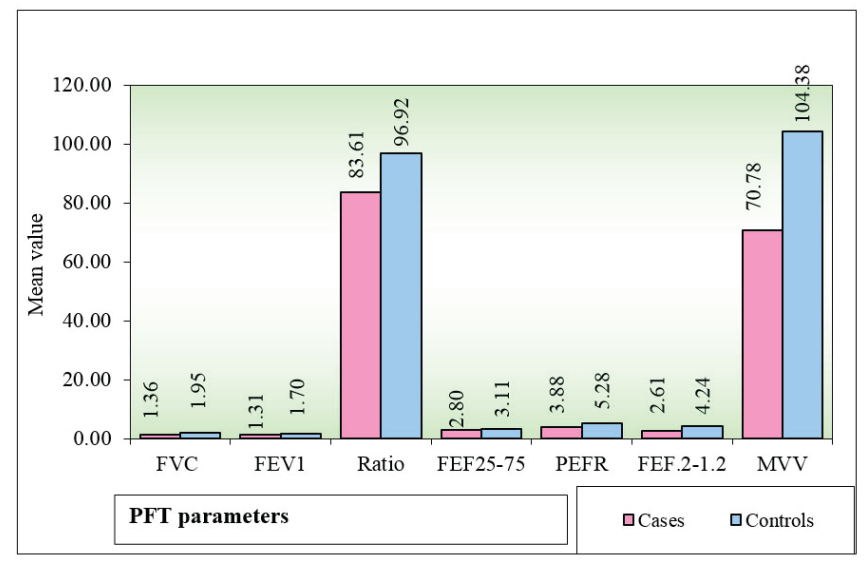

Graph II: Comparison of PFT parameters in tobacco users and nonusers in females

\section{DISCUSSION}

In our study we found that there was no significant difference in the anthropometric parameters of both male and female participants. There was no considerable difference between the economic status of control and study group of individuals.

In this study we observed that in both male and female participants there was reduction in all the PFT parameters including FVC, $\mathrm{FEV}_{1}, \mathrm{FEF}_{25-75}, \mathrm{FEF}_{2-1.2 .}$, PEFR and MVV in tobacco chewers compared to non chewers. The reduction was statistically significant $(p<0.001)$. There was also reduction in $\mathrm{FEV}_{1} / \mathrm{FVC}$ ratio but it was not up to statistically significant level in males but was statistically significant in females. Reduction in all PFT parameters except FEV1/FVC in male tobacco chewers suggests restrictive impairment in lung functions.

A study done by Pramanik P., has reported similar results in khaini users where all pulmonary function indices except $\mathrm{FEV}_{1} / \mathrm{FVC}$ showed statistically significant difference be- tween 'khaini' users and nonusers. They attributed it to be due to a lack of intake of antioxidant rich food in their diet. This makes them more vulnerable to tobacco-induced oxidative stress. Thus 'khaini' induced low pulmonary function indices may be due to increased oxidative stress ${ }^{1}$.

In India it has been estimated that roughly one third of women and two-thirds of men use tobacco in one form or another. Prevalence surveys in eight rural areas of India have shown that smokeless tobacco use was 53\% among men and 49\% among women. (WHO 1997) The various forms in which tobacco is consumed are chewed form, sucked or applied to teeth and gums. About $35-40 \%$ of tobacco consumption in India is in smokeless forms. ${ }^{6}$

Previous studies have shown that low pulmonary function indices in smokeless tobacco users may be attributed to oxidative stress resulting from imbalance between formation of reactive oxygen species and antioxidants which may contribute to inflammation and chronic airway limitation. ${ }^{6}$

Thus in our study, the low pulmonary function indices in tobacco chewers may be attributed to increased oxidative stress. ${ }^{7}$ Similar findings were found by other studies.

It has been found in a study that there is an association between tobacco chewing and oral cancer, hypertension, heart disease and other conditions. Respiratory system is also likely to be affected by it ${ }^{7}$. In our study similarly we also found affection of respiratory system in tobacco chewers.

There is a potential role of oxidative stress in airway obstruction. Inactivation of antiproteases, inflammation, infection, direct cell damage, and disturbances in the antioxidant defense are primary mechanisms that appear to be involved in tobacco chewers ${ }^{8,9}$. Oxidative stress can cause inflammation of respiratory epithelial cells and morphologic changes that may lead to airway obstruction and ultimately alter pulmonary function ${ }^{10,11}$.

\section{CONCLUSION}

Thus in our study, we observed significant reduction in all the pulmonary function test parameters except $\mathrm{FEV}_{1} / \mathrm{FVC}$ in tobacco chewers compared to non tobacco chewers suggesting restrictive impairment in lung functions. The reduction in values of pulmonary function test parameters in tobacco chewers suggests there occurs adverse effect on lung function by the use of smokeless tobacco.

Hence we conclude that the use of smokeless tobacco in the form of chewing has deleterious effects on lung functions and hence smokeless tobacco should not be considered as a safe alternative to smoking. Due to the large number of tobacco chewers in our country, further studies may be required to identify the effects of tobacco chewing not only on 
pulmonary functions but also on other systems of the body.

Acknowledgement: We are thankful to the institution's research department for giving permission to carry out this study and the head of Department of Physiology for providing us all the laboratory facility for carrying out this work. We are also thankful to laboratory technicians for their valuable help.

The authors gratefully acknowledge all volunteers for participation in this study. We acknowledge the immense help received from the scholars whose articles are cited and included in references of this manuscript. The authors are also grateful to authors / editors / publishers of all those articles, journals and books from where the literature for this article has been reviewed and discussed.

Source of Funding: Self funded.

Conflict of Interest: None.

\section{REFERENCES}

1. Pramanik P. Effect of khaini- a form of smokeless chewing tobacco on pulmonary functions. Indian J Physiol Pharmacol 2013; 57(1): 84-6.

2. Gupta G, Goyal K, Gupta R. Pulmonary Functions in Smokeless Tobacco Users in Haryana. International J. of Health Sciences and research 2016; Vol.6(6):106-12.

3. Vijaykumar Nand Badiger S. Effect of acute and chronic nicotine consumption on reaction time. Al Ameen J Med Sci 2015; $8(3): 179-183$

4. Devendra Kumar, Binawara B.K., Acharya, Maan B. Effect of chewing tobacco on pulmonary functions in Bikaner city population. IRPMS VOL-2(5), Jan-Mar 2017
5. Brusasco V, Gapo R, Viegi G. Standardization of spirometry. Series "ATS/ERS task force: Standardization of lung function testing”. Eur Resp J 2005; 26: 319-38. Material and methods American society.

6. Ahuja A, Uppe A, Nair G: Study of lung functions in tobacco chewers. International Journal of Current Research. Vol. 8, Issue, 07, pp.34334-34337, July, 2016

7. World Health Organization. WHO Report on Global Epidemic: Warning about Dangers of Tobacco Geneva. World Health Organization 2011

8. X Y Li, P S Gilmour, K Donaldson 1996. Free radical activity and pro-inflammatory effects of particulate air pollution (PM10) in vivo and in vitro. Thorax, 51:1216-22.

9. R J Pritchard, A J Ghio, J R Lehmann: 1996. Oxidant generation and lung injury after particulate air pollutant exposure increase with the concentrations of associated metals. Inhal Toxicol., 8:457-77.

10. Bast A, Haenen G R M M, Doelman C J A. 1991. Oxidants and antioxidants: state of the art. Am J Med., 91(suppl):2S-13S.

11. Cantin A, Crystal R G. 1985. Oxidants, antioxidants, and the pathogenesis of emphysema. Eur J Respir Dis., 66:7-17.

12. Crystal R G. 1991. Oxidants and respiratory tract epithelial injury: pathogenesis and strategies for therapeutic intervention. Am J Med., 91(suppl):39S-44S.

13. Lam E W N, Kelly E E, Martin S M, Buettner G R: Tobacco Xenobiotics release nitric oxide. Tob induced Dis 2011;1(3): 207-11.

14. Bagchi M, Balmoori J, Bagchi D, Stohs S J, Chakrabarti J, Das D K: Role of reactive oxygen species in the development of cytotoxicity with various forms of chewing tobacco and pan masala. Toxicology 2002;179:247-55.

15. Patil S S, Patil S. N, Somade P. M.: Comparative study of Pulmonary Function tests in Tobacco chewers and non tobacco chewers. Indian Journal of Basic and Applied Medical Research; December 2018: Vol.-8, Issue- 1, P. 208-214. 